\title{
Occupational therapy hand assessment practices: Cause for concern?
}

\author{
Susan de Klerk, B OT (SU), DHT (UP), M OT (SU) \\ Lecturer, Division of Occupational Therapy, Department of Interdisciplinary Health Sciences, Stellenbosch University.
}

\author{
Helen Buchanan, B Sc OT (UCT), M Sc OT (UCT), PhD OT (UCT) \\ Senior Lecturer, Division of Occupational Therapy, Department of Health and Rehab Sciences, University of Cape Town
}

Blanche Pretorius, Dip OT (UP), PGDTE (UP), PGD PME (SU) BAHons (UNISA), MEd (SU)

Part Time Lecturer, Division of Occupational Therapy, Department of Interdisciplinary Health Sciences, Stellenbosch University

Introduction: Assessment is critical for measuring improvement, or lack thereof, and demonstrating the outcome of intervention. In response to the lack of research in this area, this study aimed to determine the assessment practices of occupational therapists working with clients with hand conditions.

Methods: A quantitative cross sectional survey design was used. A convenience sample of occupational therapists was recruited from five provinces. Respondents completed a questionnaire developed for the study that comprised demographic information, assessments used, frequency of use and factors influencing assessment choice. Data were analysed with Statistica version II.

Results: Eighty-one respondents $(n=1 / 4)$ completed questionnaires representing a $7 / \%$ response rate. Goniometry (84.0\%), manual muscle testing $(76.5 \%)$ and testing for flexor tendon function $(76.3 \%)$ were used most frequently. The most common reasons for not using assessments were lack of availability and unfamiliarity.

Conclusion: It is of concern that the assessment practices of participants in this study focussed primarily on the assessment of body function and structure with few therapists using activity and participation measures. This could seriously limit the evidence needed to verify the outcomes achieved through occupational therapy intervention in the treatment of hand conditions.

Key words: hand assessment, occupational therapy, body structure and function, activity, participation

\section{INTRODUCTION}

Assessment is an integral part of the occupational therapy process and a necessity for evidence based practice'. Without appropriate measurement, therapists cannot provide evidence for interventions offered. Information obtained through standardised assessment provides reliable data that can assist therapists in justifying occupational therapy services ${ }^{2}$. Dunn ${ }^{3}$ suggested two primary reasons for using assessment in practice. Firstly, assessment provides evidence of the difficulties a client is experiencing in order to plan effective intervention. Secondly, appropriate assessment enables client-centeredness through involving the individual in making decisions about the most suitable intervention. Therapists need to use appropriate and relevant assessments and document them clearly so that client progress can be monitored to ensure they are receiving the best possible intervention. Occupational therapy assessments may be non-standardised (or informal) or standardised; each being used for different reasons. An assessment tool is standardised if validity, reliability, sensitivity and clinical utility have been established ${ }^{4}$. In practice situations in which standardised assessments are inappropriate or not available, informal (non-standardised) assessments, such as skilled observations or interviews, may be used ${ }^{3}$. Dunn ${ }^{3}$ advocated measuring the outcome of therapy in order to "know the end result and how [the intervention] went" ${ }^{\text {"2: }}$. The impact of services can therefore be determined if outcome measures are routinely used. Outcome measures are in effect standardised assessments that are able to identify changes that occur as a result of the intervention ${ }^{5}$.

Failing to use appropriate assessment tools in daily practice has far-reaching implications. In environments that are increasingly driven by legislation, such as those in which occupational therapists practice in South Africa, there is an increased mandate to produce evidence of the interventions provided ${ }^{5}$. If therapists do not assess, they will not be able to produce evidence of the effects of the interventions offered which poses a threat to funding of services. This claim is supported in the Western Cape Department of Health Healthcare 2030 plan $^{6}$ that states that there will be an increased move towards outcome based intervention with priority being given to interventions aimed at desirable outcomes. At the time of conducting this study, no research to determine the assessment practices of occupational therapists working with hand conditions within South Africa had been published. Assessment practices are understood to encompass the type of assessment used, the frequency of use and the reasons for non-use within a particular area of practice. This study therefore set out to provide an updated account of these practices by South African occupational therapists working with clients with hand conditions.

\section{LITERATURE REVIEW}

A client-centred approach should be applied in assessment to obtain a "careful understanding" of the individual before starting occupational therapy intervention ${ }^{7: 253}$. This type of approach is more likely to ensure that the client is engaged in the occupational therapy process which will encourage greater client cooperation ${ }^{8}$. In a client-centred approach, the client and therapist work together to establish the occupational performance problems and to set goals for the required intervention. Assessment has to take place for this to be possible. Standardised assessment provides quantitative information, useful for tracking the client's progress and demonstrating the outcome of therapy'. However, research studies have shown that standardised assessments are often not used routinely in practice. In a rheumatology study conducted in the 
United Kingdom the authors found that standardised assessments were hardly used by occupational therapists $(n=114)$, with $14 \%$ using them to identify difficulties in activities of daily living (ADLs) and $8 \%$ to evaluate the effect of interventions addressing $A D L^{9}$. Reasons for non-use were 'lack of knowledge about availability' and 'lack of appropriate training".

Extensive research into assessment practices has been done in Australia, Ireland, England, the United States of America and Canada ${ }^{4,9-17}$. These studies investigated general assessment use, and included health care workers in addition to occupational therapists. All the studies concluded that there was a lack of familiarity and limited use of appropriate assessment tools. In addition, although participants acknowledged the importance of standardised assessments, they continued to rely on subjective assessments.

\section{What should be assessed?}

The introduction of the International Classification of Functioning, Disability and Health (ICF) ${ }^{18}$ changed the way in which assessments are approached ${ }^{19}$. As the ICF provides a framework for understanding the impact of the health condition on functioning and disability, it is no longer acceptable to focus purely on health outcomes following surgical, medical or therapeutic interventions. In MacDermid's ${ }^{19}$ opinion, hand therapists typically focus on changes in physical impairments - the body function and body structure components of the ICF framework - as the primary measures of outcome. Strong arguments have been made for assessment information that reflects clients' abilities to perform their occupations in addition to symptoms (body function and structure $)^{20}$. Inclusion of such tests enables decisions to be made about interventions that address activity and participation, and allows therapists to track client progress and evaluate the effectiveness of the intervention provided ${ }^{20}$. However, this is not necessarily applied in research or practice. For example, a systematic review of randomised controlled trials (RCT's) of interventions for hand injuries showed that few studies used instruments measuring both activity and participation ${ }^{21}$. A more recent systematic review of hand assessments identified 15 tools that assess activity and participation but most had poor clinimetric properties, including validity, reliability and responsiveness ${ }^{22}$. Tools need to have good clinimetric properties in order to be able to evaluate change and, in some instances, to predict outcomes of therapy ${ }^{20}$. To investigate whether additional information on hand assessment tools had been published since Schoneveld et al's2 ${ }^{22}$ systematic review, the first author conducted a literature search to identify upper limb assessment tools for use with injuries to a nerve or tendon, and for upper limb fractures. Such tools are in demand in South Africa as muscle, bone and peripheral nerves are among the most prominent structures injured and/or affected in hand conditions. Twenty-one articles ${ }^{19,20,22-40}$ reporting II tools were identified. The tools were framed within the ICF (see Table I).

\section{Selection criteria for assessment tools}

It is critical that assessment tools with strong clinimetric properties are used so that the assessment findings can be used to evaluate the outcome of therapy services. This requires therapists to evaluate the properties of a tool to reach a decision about its suitability for the context and purpose. Law' developed an algorithm to aid therapists in evaluating specific assessment tools. This process involves firstly establishing its clinical utility, then determining whether it is standardised or not, and lastly, evaluating the purpose of the tool. Jerosch-Herold ${ }^{49}$ similarly advocated for considering pragmatic factors, including the portability of the test, its cost, acceptability and ease of use, as well as the clinimetric properties of validity, reliability and responsiveness. She devised a structured checklist to assist researchers and clinicians in evaluating the clinimetric properties required in a robust outcome measure in order to choose the most appropriate tool ${ }^{49}$.

This literature review has shown that while suitable tools for hand assessment are available, their usage by occupational therapists in developed countries is low. As no research about hand assessment practices in developing contexts was found, the objectives of this study were to identify the hand assessment tools used by South African occupational therapists, their frequency of use, and reasons for non-use.

\section{METHODOLOGY}

\section{Study design}

A quantitative cross sectional survey design was employed.

\section{Population and sampling}

The population targeted all occupational therapists in South Africa involved in treating people with hand injuries between March and May 2013. As there was no comprehensive list of these therapists available, membership information was obtained from the South African Society of Hand Therapists (SASHT) and the Occupational Therapy Association of South Africa (OTASA). The SASHT had I 3 I occupational therapist members from five provinces in 2012 and the OTASA had a list of 243 therapists who indicated hand therapy as a specialisation in $2013^{50,51}$. There was some duplication as SASHT members may also have been OTASA members. In addition, there were also likely to be therapists practising within this field who were not members of either association. As a result, there was uncertainty as to the exact number in the population. Convenience sampling was therefore used to recruit as many therapists as possible. To be included, respondents had to be qualified occupational therapists, registered with the Health Professions Council of South Africa, and working with hand conditions at the time of the study. Therapists attending continuing professional development (CPD) courses (mostly related to the field of hand therapy) were approached and presented with the questionnaire at the CPD opportunity. Students enrolled in post graduate studies specialising in hand conditions from the University of Pretoria were also approached with the consent of the course convenor $(n=|| 4)$.

\section{Instrumentation}

Data were collected with a self-administered questionnaire developed for the study. The questionnaire comprised three sections

Table I: Assessment tools framed within the ICF for specific conditions

\begin{tabular}{|c|c|c|}
\hline \multirow{2}{*}{ Condition } & \multicolumn{2}{|c|}{ Assessment tools framed within the ICF } \\
\hline & Body Function and Structure & Activity and Participation \\
\hline Nerve or Tendon Injury & $\begin{array}{l}\text { - Range of Motion (goniometry) } \\
\text { - Strength (manual muscle testing and/or } \\
\text { dynamometry) } \\
\text { - Sensibilitity (monofilament testing and/or } \\
\text { traditional sensation tests) }\end{array}$ & $\begin{array}{l}\text { - Sollerman Test of Hand Function }{ }^{35} \\
\text { - Moberg Pick Up Test' } t^{33,34} \\
\text { - Nine Hole Peg Test }{ }^{43} \\
\text { - Jebsen-Taylor Test of Hand Function }{ }^{44} \\
\text { - Disability of the Arm, Shoulder and Hand Questionnaire } \\
\text { (DASH) })^{45}\end{array}$ \\
\hline $\begin{array}{l}\text { Fracture of the upper } \\
\text { limb }\end{array}$ & $\begin{array}{l}\text { - Range of Motion (goniometry) } \\
\text { - Strength (manual muscle testing and/or } \\
\text { dynamometry })^{24,42}\end{array}$ & $\begin{array}{l}\text { - Jebsen-Taylor Test of Hand Function }{ }^{44} \\
\text { - DASH }{ }^{45} \\
\text { - Short Form-3646 } \\
\text { - Smith Hand Function Evaluation }{ }^{47} \\
\text { - Patient Rated Wrist Evaluation (PRWE) }\end{array}$ \\
\hline
\end{tabular}


similar to the questionnaire used by Stapleton and McBrearty in their investigation of standardised assessments in a sample of Irish occupational therapists ${ }^{17}$. The first section of the questionnaire contained demographic information so that a demographic profile of the respondents could be established. The second section contained a list of 44 assessment tools. Respondents indicated the frequency of using these tools on a five-point Likert scale, along with possible reasons for not using these tools frequently. The third section explored the possible factors impacting the frequency of using the measurement tool. The questionnaire included closed questions as they require less time to complete, are easy to analyse and provide specific information ${ }^{52}$. The researcher did however provide an option which enabled respondents to specify or add 'other' in sections two and three. The 'other' option, with space to add text, allowed respondents to add information on additional measurement tools (section two) or factors (section three) not included in the final questionnaire. In doing this, bias was reduced and content validity increased as respondents could add information that was relevant to them. The list of assessment tools was compiled from information in the literature review, feedback from the pilot testing of the questionnaire, and personal experience in the field of hand therapy.

\section{Pilot testing}

The questionnaire was piloted to check face validity and content validity. Three occupational therapists from different practice settings participated. Two respondents had more than 20 years of hand therapy experience in private and government practice settings, and one had more than I 5 years' experience in upper limb assessment as part of work evaluations in private practice. Respondents completed the questionnaire after which telephonic interviews were conducted with two of the respondents and a face-to-face interview with one. Feedback from the pilot test was used to make minor amendments to the wording in the questionnaire. For example, names of specific tests (Landmark Test, Volumeter and Figure-of-8 Measurement) were added to the section on oedema measurement ${ }^{53,54}$.

\section{PROCEDURE}

Data were collected over a three month period from March to May 20I3. To recruit as many respondents over this period as possible, questionnaires were distributed to:

* Occupational therapists attending CPD courses presented by the SASHT in the Western Cape and Gauteng (these were the only two provinces where courses were held during the data collection period);

* Occupational therapists enrolled for the Postgraduate Diploma in Hand Therapy at the University of Pretoria;

* Attendees of a course offered by the Occupational Therapy in Occupational Health special interest group in Cape Town to include therapists assessing the hand as part of work assessment practices.

* SASHT members in three provinces where SASHT courses were not offered during the period of data collection (KwaZulu-Natal, the Northern Cape and the Eastern Cape) were invited to participate and asked to distribute the questionnaire to colleagues treating clients with upper limb conditions in private practice and government settings.

Questionnaires were accompanied by an information leaflet and consent form. The signed consent form was returned with the completed questionnaire.

\section{Data management and analysis}

Data were entered into Microsoft Excel and checked for accuracy. Analyses were performed in Statistica (ver II - 20I3), with the assistance of a statistician. As there were some cells with few responses, categories in section two of the questionnaire were collapsed from five to three for the purpose of analysis. The new categories were 'not used at all' (unchanged), 'used infrequently' ('seldom' and 'sometimes' combined) and 'used frequently' ('fre- quently' and 'very frequently' combined). As continuous data were not normally distributed, medians and ranges were calculated. Frequencies and proportions were calculated for categorical variables.

\section{Ethics}

Permission to conduct the research was obtained through the Health Research Ethics Committee of Stellenbosch University (ethics reference number: SI3/02/029). Confidentiality and anonymity were maintained throughout the research process. The researcher kept the information in a secure place to which no other person had access. A code was assigned to each participant on the questionnaire to ensure that respondents' names were not on the questionnaire.

\section{RESULTS}

Of I 4 therapists who were approached to participate, 8 I completed and returned questionnaires, representing a response rate of $71 \%$. All questionnaires were included in the analysis and missing data are reported per question. Missing data ranged between 0 and I I for each question. Although there were missing data in each section of the questionnaire, all questionnaires were included in the analysis. Frequencies were calculated for each assessment included in the questionnaire, irrespective of the number of responses for that particular assessment.

\section{Demographic and practice profile}

Respondents' demographic characteristics are shown in Table II. The median for experience in the field of hand therapy was 2.5 years. Most participants worked in private practice settings $(60.5 \%)$ and qualified at Stellenbosch University (28.4\%). Few had post graduate qualifications (Diploma or Master's degree) in hand therapy (I8.5\%). Respondents represented five provinces within South Africa.

Table II: Demographic Variables for Respondents $(n=8 I)$

\begin{tabular}{|l|c|}
\hline Variable & Median (Min-max) \\
\hline Years of practice as an OT & $5.0(0.4-33.0)$ \\
\hline Years of practice in hand therapy & $2.5(0.4-26.0)$ \\
\hline Practice setting & No. (\%) \\
\hline Government sector & $32(39.5)$ \\
\hline Private sector & $49(60.5)$ \\
\hline Total & $81(100.0)$ \\
\hline Institution for OT qualification & $14(17.3)$ \\
\hline University of Pretoria & $10(12.4)$ \\
\hline University of Witwatersrand & $12(14.8)$ \\
\hline University of Cape Town & $12(14.8)$ \\
\hline University of Free State & $23(28.4)$ \\
\hline Stellenbosch University & $6(7.4)$ \\
\hline University of the Western Cape & $3(3.7)$ \\
\hline University of KwaZulu Natal & $1(1.2)$ \\
\hline University of Limpopo & $81(100.0)$ \\
\hline Total & $12(80.0)$ \\
\hline Post graduate qualification & $15(18.5)$ \\
\hline Yes & $66(81.5)$ \\
\hline No & $81(100.0)$ \\
\hline Total & \\
\hline Type of post graduate qualification in hand therapy \\
\hline Diploma in Hand therapy & \\
\hline Masters in Hand therapy & \\
\hline Total & $100.0)$ \\
\hline
\end{tabular}


The specific diagnoses treated regularly or areas of day-to-day practice are shown in Figure $I$. The diagnoses that were seen most commonly were nerve injuries $(90.1 \%)$, fractures $(88.8 \%)$ and tendon injuries (85.1\%).

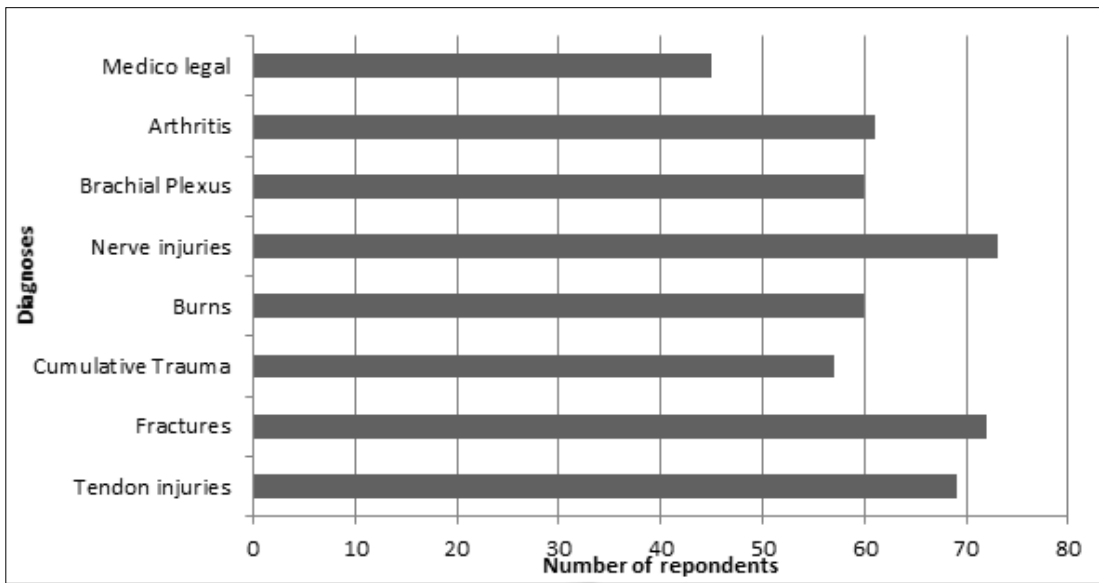

Figure I: Diagnoses treated or area practiced in by respondents $(n=8 I)$
Choice of assessments and frequency of use

Assessment tools were categorised into two groups based on whether they measured 'body function and structure' (Figure II) or 'activity and participation' (Figure III). Decisions about categorising each tool were based on published articles that investigated hand assessment tools framed within the ICF $19,20,22,55-57$. The most popular assessment tools for assessing aspects of body function and structure (Figure II) were goniometr $^{4 l}$ (84.0\%), manual muscle testing ${ }^{24}(76.5 \%)$ and testing for flexor digitorum profundus (FDP) and superficialis (FDS) function ${ }^{58}(76.3 \%)$.

For activity and participation, a relatively high percentage of respondents used the Disability of the Arm Shoulder and Hand (DASH) ${ }^{45}$ questionnaire infrequently (40.0\%) or not at all (36.3\%). (see Figure III).

Sixteen of the measures of activity and participation were not used at all by 50 or more respondents (see Figure III). The highest percentage of non-use included the Hand Assessment Tool (HAT) $)^{59}$

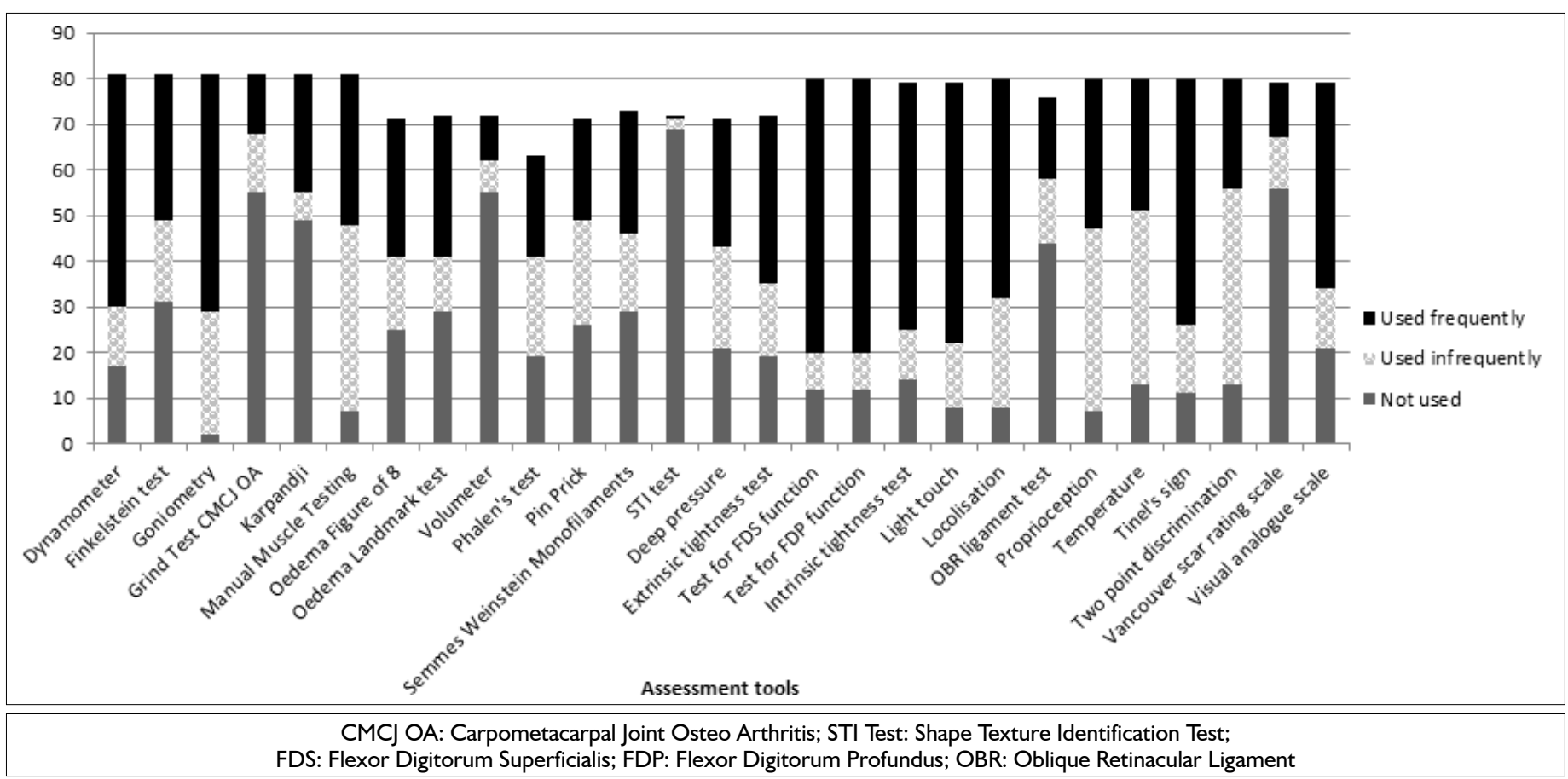

Figure II: Assessment tools for body structure and function

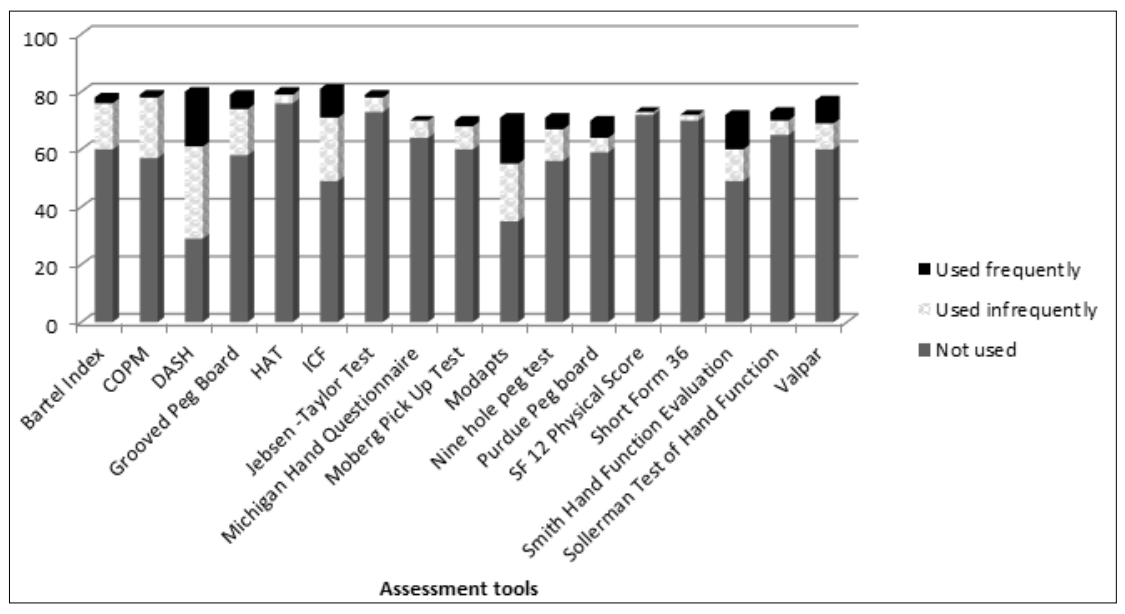

COPM: Canadian Occupational Performance Measure; DASH: Disability of the Arm, Shoulder and Hand Questionnaire; HAT: Hand Assessment Tool; ICF: International Classification of Functioning Disability and Health; SF: Short Form

Figure III: Assessment tools for activity and participation
(95.0\%), Jebsen - Taylor Test of Hand Function ${ }^{44}$ (92.4\%), Short Form- I2 Physical Score ${ }^{60}$ (98.6\%) and Short Form-36 66 (97.2\%).

\section{Reasons for non-use}

Reasons for not using assessments are presented in Table III on page 47. The most common reasons for non-use were lack of availability in the practice area and lack of familiarity with the assessment tool. The 'not applicable' responses indicate the number of respondents who used the assessment tool frequently and therefore did not have to provide a reason for non-use. Although respondents could provide more than one reason for non-use, no-one did.

\section{DISCUSSION}

The first objective of this study was to identify the frequency of use of hand assessment tools by occupational therapists. In order to address this objective it is important to consider the conditions that 
Table III: Reasons for not using tools assessing activity and participation

\begin{tabular}{|c|c|c|c|c|c|c|c|c|}
\hline & $\begin{array}{l}\text { Missing } \\
\text { responses }\end{array}$ & $\begin{array}{c}\text { Not } \\
\text { available }\end{array}$ & No training & $\begin{array}{l}\text { Monetary } \\
\text { constraints }\end{array}$ & $\begin{array}{c}\text { Time } \\
\text { constraints }\end{array}$ & $\begin{array}{l}\text { Not } \\
\text { applicable in } \\
\text { setting }\end{array}$ & Not familiar & $\begin{array}{c}\text { Not } \\
\text { applicable } \\
\text { responses }\end{array}$ \\
\hline & No. (\%) & No. (\%) & No. (\%) & No. (\%) & No. (\%) & No. (\%) & No. (\%) & No. (\%) \\
\hline Grooved peg board ${ }^{61}$ & $2(2.5)$ & $38(46.9)$ & $4(4.9)$ & $\mathrm{I}(1.2)$ & $5(6.2)$ & $3(3.7)$ & $14(17.3)$ & $14(17.3)$ \\
\hline $\begin{array}{l}\text { Moberg Pick Up } \\
\text { Test }^{33,34}\end{array}$ & $11(13.6)$ & $33(40.7)$ & $5(6.2)$ & $2(2.5)$ & $2(2.5)$ & $2(2.5)$ & $19(23.5)$ & $7(8.6)$ \\
\hline Short form $36^{46}$ & $9(11.1)$ & $24(29.6)$ & $5(6.2)$ & $0(0.0)$ & $\mathrm{I}(\mathrm{I} .2)$ & $3(3.7)$ & $36(44.4)$ & $3(3.7)$ \\
\hline MODAPTS $^{62}$ & $10(12.3)$ & $18(22.2)$ & $2(2.5)$ & $\mathrm{I}(\mathrm{I} .2)$ & $13(16.0)$ & $8(9.9)$ & $4(4.9)$ & $25(30.9)$ \\
\hline Nine Hole Peg Test ${ }^{43}$ & $10(12.3)$ & $35(43.2)$ & $4(4.9)$ & $\mathrm{I}(1.2)$ & $7(8.6)$ & $4(4.9)$ & $12(14.8)$ & $8(9.9)$ \\
\hline Purdue Peg Board63 & II (13.6) & $40(49.4)$ & $2(2.5)$ & $\mathrm{I}(1.2)$ & $4(4.9)$ & $3(3.7)$ & $12(14.8)$ & $8(9.9)$ \\
\hline $\begin{array}{l}\text { Smith Hand Function } \\
\text { Evaluation }^{47}\end{array}$ & $9(11.1)$ & $33(40.7)$ & $\mathrm{I}(\mathrm{I} .2)$ & $2(2.5)$ & $8(9.9)$ & $3(3.7)$ & $6(7.4)$ & $19(23.5)$ \\
\hline $\begin{array}{l}\text { Sollerman Test of } \\
\text { Hand Function }\end{array}$ & $8(9.9)$ & $38(46.9)$ & $2(2.5)$ & $3(3.7)$ & $2(2.5)$ & $0(0.0)$ & $20(24.7)$ & $8(9.9)$ \\
\hline Valpar 64 & $4(4.9)$ & $43(53.0)$ & $4(4.9)$ & $7(8.6)$ & $5(6.2)$ & $5(6.2)$ & $2(2.5)$ & II (13.6) \\
\hline $\mathrm{ICF}^{18}$ & $0(0.0)$ & $12(14.8)$ & $8(9.9)$ & $0(0.0)$ & $21(26.0)$ & $4(4.9)$ & $14(17.3)$ & $22(27.1)$ \\
\hline HAT $^{59}$ & $\mathrm{I}(1.2)$ & $18(22.2)$ & $10(12.3)$ & $0(0.0)$ & $2(2.5)$ & $I(1.2)$ & $42(51.9)$ & $7(8.6)$ \\
\hline COPM $^{65}$ & $2(2.5)$ & $22(27.1)$ & $6(7.4)$ & $0(0.0)$ & $25(30.9)$ & $5(6.2)$ & $14(17.3)$ & $7(8.6)$ \\
\hline DASH $^{45}$ & $I(1.2)$ & $10(12.3)$ & $7(8.6)$ & $0(0.0)$ & $19(23.5)$ & $5(6.2)$ & $9(11.1)$ & $30(37.0)$ \\
\hline Jebsen-Taylor ${ }^{44}$ & $2(2.5)$ & $38(46.9)$ & $4(4.9)$ & $2(2.5)$ & $5(6.2)$ & $2(2.5)$ & $22(27.1)$ & $6(7.4)$ \\
\hline Barthel Index ${ }^{66}$ & $3(3.7)$ & $22(27.1)$ & $7(8.6)$ & $0(0.0)$ & $15(18.5)$ & $12(14.8)$ & $17(20.9)$ & $5(6.2)$ \\
\hline SF- $12^{60}$ & $8(9.9)$ & $23(28.4)$ & $4(4.9)$ & $0(0.0)$ & $\mathrm{I}(1.2)$ & $2(2.5)$ & $39(48.1)$ & $4(4.9)$ \\
\hline $\begin{array}{l}\text { Michigan Hand } \\
\text { Question }^{67}\end{array}$ & II (13.6) & $19(23.5)$ & $4(4.9)$ & $0(0.0)$ & $10(12.3)$ & $\mathrm{I}(\mathrm{I} .2)$ & $32(39.5)$ & $4(4.9)$ \\
\hline
\end{tabular}

ICF: International Classification of Functioning Disability and Health; HAT: Hand Assessment Tool; COPM:

Canadian Occupational Performance Measure; DASH: Disability of the Arm, Shoulder and Hand Questionnaire; SF: Short Form

were seen most frequently as specific assessments are indicated for particular conditions. Most time was spent treating nerve injuries (90.1\%), fractures $(88.8 \%)$ and tendon injuries (85.1\%). It was therefore expected that aspects of body function and structure as well as activity and participation would be assessed as indicated in the literature. According to MacDermid ${ }^{23}$, therapists working with clients with tendon or nerve injury should report outcomes related to activity and participation in addition to range of motion and muscle strength. Assessment of range of motion (goniometry) and strength (manual muscle testing and/or dynamometry) were used frequently by respondents in this study. However, additional assessment, such as the Michigan Hand Questionnaire ${ }^{67}, \mathrm{DASH}^{45}$ or Jebsen-Taylor Hand Function test ${ }^{44}$, is required to quantify the functional implications of these conditions ${ }^{20,22,23,29,30}$. The findings from this study, however, showed that assessments addressing activity and participation were used infrequently or not at all.

It would be expected that assessing clients with nerve injury would require measurement tools to assess range of motion, strength, sensibility (namely Semmes Weinstein monofilaments and/or traditional threshold tests) and tactile discrimination (for example, two-point discrimination, Shape Texture Identification Test (STI Test), Moberg Pick Up Test, Nine Hole Peg Test) ${ }^{19,23,29-32}$. However, the respondents in this study used these assessments infrequently or not at all. It is also clear from the literature that sensibility assessment should be graded as recovery progresses and should include threshold testing as well as functional performance tests $^{31,32}$. However, assessment of light touch was used frequently (71.3\%) in this study. The test for light touch is a sensation threshold test that is used early in the assessment of clients with peripheral nerve injuries ${ }^{68}$. As the nerve recovers and sensation improves in the predicted pattern of recovery, additional testing is required ${ }^{68}$.
In the present study, threshold tests (which are measures of body function and structure) were used frequently, but tests measuring activity and participation, particularly functional sensation testing such as the Moberg Pick Up Test ${ }^{33,34}$ and the Nine Hole Peg Test ${ }^{43}$, were used either infrequently or not at all ${ }^{1,32}$. This was surprising considering that the Moberg Pick Up Test ${ }^{33,34}$ can be constructed easily and is relevant in a variety of contexts ${ }^{32}$.

The Tests for FDS $(76.3 \%)$ and FDP function ${ }^{58}(76.3 \%)$, Test for intrinsic tightness ${ }^{69}(68.4 \%)$, and Dynamometry ${ }^{42}(63.0 \%)$ were also used frequently by the study respondents. As these tests are indicated for use with tendon injuries to assess body function and structure, either to make or confirm a diagnosis or track patient progress, it was expected that respondents would use these tests frequently $y^{23,70}$. It is however concerning that additional testing such as the Michigan Hand Questionnaire ${ }^{67}$ that was found responsive to report on activity and participation outcomes in tendon injuries, were used infrequently or not at all ${ }^{22,23}$.

Measurement of the effects of an upper limb fracture should include a combination of assessments of body function and structure (range of motion and strength) and activity and participation (using self-report questionnaires such as the DASH ${ }^{45}$ or Short Form$\left.36^{46}\right)^{37,40}$. Some respondents used the $D A S H^{45}$ with some frequency, but other measures of activity and participation indicated for this diagnostic group, such as the Short Form $-36^{46}$, was used infrequently or not at all.

Although the assessment tools that were used frequently in this study are supported by the literature with regard to the diagnostic groupings seen by the respondents in their clinical practice, the lack of tools measuring activity and participation is not in line with recommendations in the literature and is therefore a cause for concern ${ }^{20,22,23,56,57}$. These recommendations have been supported 
by Law' who stated that the additional tests are needed to evaluate the impact on occupational performance ${ }^{8,23}$. The researcher expected to find frequent use of additional tests such as the $D A S H^{45}$, The Michigan Hand Questionnaire ${ }^{67}$ or the Jebsen-Taylor Hand Function Test ${ }^{44}$ in conjunction with measurements of range of motion or muscle strength; however this was not the case.

The second objective of this study was to identify the reasons for non or infrequent use of assessment tools. The four tools that were least used or not used at all were assessments of activity and participation, namely the Hand Assessment tool (HAT) ${ }^{59}$, Jebsen - Taylor Test of Hand Function ${ }^{44}$, SF- 22 Physical Score ${ }^{60}$ and Short Form $-36^{46}$. Other tests of activity and participation that were not used at all were the Smith Hand Function Evaluation ${ }^{47}$ (68.1\%), the Sollerman Test of Hand Function ${ }^{35}$ (89.0\%), the Nine Hole Peg Test $^{43}(78.9 \%)$ and the Moberg Pick Up Test ${ }^{33,34}$ (85.7\%). The study showed that although these tests have standardised procedures, they were not used frequently by the study respondents mostly due to lack of familiarity or unavailability. This supports the findings of similar studies conducted abroad ${ }^{12,16,17}$. The current research did not consider therapists' attitudes towards using appropriate assessment tools for hand conditions. Therefore non-use is not necessarily a reflection of their assessment practices but may indicate problems with the availability of these tools in clinical practice, or training offered in the use of these tools at undergraduate or postgraduate level. As these aspects were not investigated in this study, further conclusions cannot be drawn.

It is however a cause for concern that most respondents primarily used tests of body function and structure. Discriminative measurement tools were used frequently for nerve injuries, tendon injuries and fractures of the upper limb; these are also used by hand surgeons and other health professionals which suggest possible duplication in the assessments conducted with clients. The lack of emphasis on assessments of activity and participation by occupational therapists, is worrying considering that this is a fundamental goal of occupational therapy ${ }^{2,7,8}$.

\section{Strengths and limitations}

The use of convenience sampling may have skewed the results as respondents were mostly therapists attending continued professional development workshops or enrolled for a postgraduate diploma in hand therapy, and may have been more unlikely to be familiar with the assessment tools in the questionnaire. Therapists who did not attend these workshops may have been more experienced in the field of hand therapy and/or with the assessment tools in question which would have yielded different results. The convenience nature of the sample suggests that the results cannot be generalised to the population of occupational therapists treating hand conditions in South Africa. Furthermore, the representativeness of this sample is uncertain as many of the respondents had very little hand therapy experience, qualified from one university, were largely from private practice settings and represented only five provinces. Therefore caution should be exercised in generalising the results to all South African occupational therapists working in this field.

\section{CONCLUSION}

This study set out to identify the assessments used in everyday practice by occupational therapists working with clients with hand injuries according to the domains of the ICF. Of the 44 measurement tools included in the questionnaire, those reporting body function and structure were used most frequently. Respondents were not using assessments of activity and participation in their daily practice supporting previous international studies that showed that standardised assessments of activity and participation are not used in routine practice. The implications for these findings within the South African context are far-reaching in that occupational therapists should be gathering evidence for the interventions provided in all practice settings. This evidence should encompass the effect of intervention on activity and participation of hand injured clients. Therefore, therapists must make use of standardised as- sessments that can provide information on activity and participation in order to gather evidence about the outcomes of interventions. The study findings suggests that further opportunities should be created within CPD programmes and postgraduate education to strengthen occupational therapy hand assessment practices. More emphasis should be placed on educating undergraduate students in the use of standardised assessments particularly those measuring activity and participation. Further research should address therapists' attitudes regarding the use of appropriate tools, and identify appropriate tools for measuring aspects of activity and participation in the South African context.

\section{REFERENCES}

I. Law M. Measurement in occupational therapy: Scientific criteria for evaluation. Canadian Journal of Occupational Therapy, 1987; 54(3): I 33-138.

2. Roley SS, DeLany JV, Barrows CJ, Brownrigg S, Honaker D, Sava DI, et al. Occupational therapy practice framework: domain \& practice, 2nd edition. American Journal of Occupational Therapy, 2008 Nov-Dec; 62(6): 625-683.

3. Dunn W. Measurement Issues and Practices. In: Law M, Baum C, Dunn W, editors. Measuring Occupational Performance: Supporting best practices in occupational therapy. Second ed. USA: Slack Incorporated; 2005: 21-32.

4. Corr S, Siddons L. An introduction to the selection of outcome measures. The British Journal of Occupational Therapy, 2005; 68(5): 202-206.

5. Van Niekerk L. Guest Editorial I-Research in Occupational Practice. South African Journal of Occupational Therapy, 20I2; 4 I (3): I.

6. Western Cape Goverment Department of Health (WCDoH). HEALTH CARE 2030.

7. Law M. Client-Centred Practice: What Does It Mean and Does It Make a Difference?. Canadian Journal of Occupational Therapy, 1995; 62(5): 250-257.

8. Law MC, Baum CM, Dunn W. Measuring occupational performance: Supporting best practice in occupational therapy, Second ed. USA: Slack Incorporated; 2005

9. Blenkiron EL. Uptake of Standardised Hand Assessments in Rheumatology: Why is it So Low? The British Journal of Occupational Therapy, 2005 ;68(4): 148-157.

10. Shanahan M. Objective and holistic? Is this occupational therapy assessment in Ireland? Irish Journal of Occupational Therapy. 1992 1992; 22(2): 8-10.

II. Cook C, McCluskey A, Bowman J. Occupational therapists report increased use of outcome measures after participation in an education programme. The British Journal of Occupational Therapy, 2007; 70(I I): 487-492.

12. Bowman J. Challenges to measuring outcomes in occupational therapy: a qualitative focus group study. The British Journal of Occupational Therapy, $2006 ; 69$ (10): 464-472.

I3. Brangan J, O'Neill G. Assessment practices of Irish occupational therapists: a study. International Journal of Therapy and Rehabilitation, 1998; 5(I I): 565-585.

14. Changulani M, Okonkwo U, Keswani T, Kalairajah Y. Outcome evaluation measures for wrist and hand-which one to choose? International Orthopaedics, 2008; 32(I): I-6.

15. Skinner A, Turner-Stokes L. The use of standardized outcome measures in rehabilitation centres in the UK. Clinical Rehabilitation. 2006; 20(7): 609-6I5.

16. Stapleton T, Galvin M. Current practice trends among occupational therapists working in stroke care: Results of a Postal Survey. Irish Journal of Occupational Therapy, 2005; 34(I): 3.

17. Stapleton T, McBrearty C. Use of Standardised Assessments and Outcome Measures among a Sample of Irish Occupational Therapists working with Adults with Physical Disabilities. The British Lournal of Occupational Therapy, 2009; 72(2): 55-64.

18. World Health Organization. International Classification of Functioning Disability and Health Checklist. Geneva. Switzerland. World Health Organization 2001.

19. MacDermid JC. Chapter 17: Outcome measurement in the upper extremity. In: Hunter, Mackin and Callahan, editors. Hunter, Mackin \& Callahan's Rehabilitation of the Hand and Upper Extremity. $5^{\text {th }}$ 
ed. Philadelphia: Mosby, 2002: 285-295.

20. van de Ven-Stevens LA, Munneke $M$, Terwee CB, Spauwen $P H$, van der Linde $\mathrm{H}$. Clinimetric properties of instruments to assess activities in patients with hand injury: a systematic review of the literature. Archives of Physical and Medical Rehabilitation,_2009;90(I): I 5 I-169.

21. Gummesson C, Atroshi I, Ekdahl C. The quality of reporting and outcome measures in randomized clinical trials related to upperextremity disorders. Journal of Hand Surgery. 2004; 29(4): 727-734.

22. Schoneveld K, Wittink H, Takken T. Clinimetric evaluation of measurement tools used in hand therapy to assess activity and participation. Journal of Hand Therapy, 2009; 22(3): 22 I-236.

23. MacDermid JC. Measurement of health outcomes following tendon and nerve repair. Journal of Hand Therapy, 2005; 18(2): 297-3 12.

24. Hislop H, Montgomery J. Daniels and Worthington's Muscle Testing: Techniques of Manual Examination. I $^{\text {st }}$ ed. Philadelphia: WB Saunders Company, 2002.

25. Clarkson HM. Musculoskeletal assessment: joint range of motion and manual muscle strength. $2^{\text {nd }}$ ed. Maryland: Lippincott Williams \& Wilkins, 2000.

26. Dvir Z. Grade 4 in manual muscle testing: the problem with submaximal strength assessment. Clinical Rehabilitation, I997; I I(I): 36-4I.

27. Hamilton A, Balnave R, Adams R. Grip strength testing reliability. lournal of Hand Therapy, 1994; 7(3): 163-170.

28. Mathiowetz V, Weber K, Kashman N, Volland G. Adult norms for the Nine Hole Peg Test of finger dexterity. Occupational Therapy Journal of Research, 19.85; 5(I): 24-38.

29. van de Pol, Rachel J, van Trijffel E, Lucas C. Inter-rater reliability for measurement of passive physiological range of motion of upper extremity joints is better if instruments are used: a systematic review. Journal of Physiotherapy, 2010; 56(I): 7-17.

30. Stegink Jansen CW, Watson MG. Measurement of range of motion of the finger after flexor tendon repair in zone II of the hand. Journal of Hand Surgery, 1993; 18(3): 4II-4I7.

31. Rosén B, Lundborg G. A model instrument for the documentation of outcome after nerve repair. Journal of Hand Surgery, 2000; 25(3): 535-543.

32. Jerosch-Herold C. A study of the relative responsiveness of five sensibility tests for assessment of recovery after median nerve injury and repair. Journal of Hand Surgery (British and European Volume), 2003; 28(3): 255-260.

33. Moberg E. Objective methods for determining the functional value of sensibility in the hand. Journal of Bone \& Joint Surgery, British Volume. 1958; 40(3): 454-476.

34. Ng CL, Ho DD, Chow S. The Moberg pickup test: results of testing with a standard protocol. Journal of Hand Therapy, 1999; 12(4): 309-3 I 2.

35. Sollerman C, Ejeskär A. Sollerman hand function test: a standardised method and its use in tetraplegic patients. Scandinavian Journal of Plastic and Reconstructive Surgery and Hand Surgery, 1995; 29(2): 167-176.

36. Jebsen RH, Taylor N, Trieschmann RB, Trotter MJ, Howard LA. An objective and standardized test of hand function. Archives of Physical and Medical Rehabilitation, 1969; 50(6): 3II-3I9.

37. Hanson B, Neidenbach P, de Boer P, Stengel D. Functional outcomes after nonoperative management of fractures of the proximal humerus. Journal of Shoulder and Elbow Surgery, 2009; I8(4): 612-62 I.

38. Duncan RW, Freeland AE, Jabaley ME, Meydrech EF. Open hand fractures: an analysis of the recovery of active motion and of complications. Journal of Hand Surgery, 1993; 18(3): 387-394.

39. Ip $\mathrm{W}, \mathrm{Ng} \mathrm{K}$, Chow S. A prospective study of 924 digital fractures of the hand. Injury, 1996 27(4): 279-285.

40. MacDermid JC, Richards RS, Donner A, Bellamy N, Roth JH. Responsiveness of the short form-36, disability of the arm, shoulder, and hand questionnaire, patient-rated wrist evaluation, and physical impairment measurements in evaluating recovery after a distal radius fracture. I Hand Surg, 2000; 25(2): -340.

4I. Norkin CC, White DJ. Measurement of joint motion: a guide to goniometry. $4^{\text {th }}$ ed. Philadelphia: FA Davis, $201 \mathrm{I}$.

42. Mathiowetz V, Weber K, Volland G, Kashman N. Reliability and validity of grip and pinch strength evaluations. Journal of Hand Surgery 1984;9(2):222-226.

43. Grice KO, Vogel KA, Le V, Mitchell A, Muniz S, Vollmer MA. Adult norms for a commercially available Nine Hole Peg Test for finger dexterity. American Journal of Occupational Therapy, 2003; 57(5) 570-573.

44. Jebsen RH, Taylor N, Trieschmann RB, Trotter MJ, Howard LA. An objective and standardized test of hand function. Archives of Physical and Medical Rehabilitation, 1969 Jun; 50(6): 31 I-319.

45. Hudak PL, Amadio PC, Bombardier C. Development of an upper extremity outcome measure: the DASH. American Journal of Industrial Medicine, 1996; 29: 602-608.

46. Ware Jr JE, Kosinski M, Bayliss MS, McHorney CA, Rogers WH, Raczek A. Comparison of methods for the scoring and statistical analysis of SF-36 health profile and summary measures: summary of results from the Medical Outcomes Study. Medical Care, 1995: AS264-AS279.

47. Smith HB. The Smith hand function evaluation. American Journal of Occupational Therapy, 1973 Jul-Aug; 27(5): 244-25I.

48. MacDermid JC. Development of a scale for patient rating of wrist pain and disability. Journal of Hand Therapy, 1996; 9(2): I78-183.

49. Jerosch-Herold C. An evidence-based approach to choosing outcome measures: a checklist for the critical appraisal of validity, reliability and responsiveness studies. The British Journal of Occupational Therapy, 2005; 68(8): 347-353.

50. Coetzee E. Email communication. Tygerberg 2013 October 20; OTASA administrator.

5I. SASHT. Membership booklet. 2012; Available at: www.sasht.org. za (Accessed Feb 20I2).

52. Oppenheim AN. Questionnaire design, interviewing and attitude measurement. $2^{\text {nd }}$ ed. London: Continuum, 2000.

53. Megens AM, Harris SR, Kim-Sing C, McKenzie DC. Measurement of upper extremity volume in women after axillary dissection for breast cancer. Archive of Physical and Medical Rehabilitation, 200 I; 82(12): 1639-1644.

54. Pellecchia GL. Figure-of-eight method of measuring hand size: reliability and concurrent validity. Journal of hand therapy. 2003; 16(4): 300-304.

55. Kjeken I, Dagfinrud H, Slatkowsky-Christensen B, Mowinckel P, Uhlig T, Kvien TK, et al. Activity limitations and participation restrictions in women with hand osteoarthritis: patients' descriptions and associations between dimensions of functioning. Annals of the Rheumatic Diseases, 2005 Nov; 64(I I): 1633-1638.

56. Valdes K, MacDermid J, Algar L, Connors B, Cyr L, Dickmann S, et al. Hand Therapists use of Patient Report Outcome (PRO) in Practice: A Survey Study. Journal of Hand Therapy. 2014 doi: 10.1016/j. jht.2014.07.00I.

57. MacDermid JC. Patient-Reported Outcomes: State-of-the-Art Hand Surgery and Future Applications. Hand Clinic, 2014 30(3): 293-304.

58. Strickland JW, Glogovac S. Digital function following flexor tendon repair in zone II: a comparison of immobilization and controlled passive motion techniques. Journal of Hand Surgery, 1980; 5(6): 537-543.

59. Naidu SH, Panchik D, Chinchilli VM. Development and validation of the hand assessment tool. Journal of Hand Therapy, 2009; 22(3): 250-257.

60. Ware JE, Kosinski M, Keller SD. SF-12: How to score the SF-12 physical and mental health summary scales. Health Institute: New England Medical Center, 1995.

61. Bryden P, Roy E. A new method of administering the Grooved Pegboard Test: performance as a function of handedness and sex. Brain Cognition, 2005; 58(3): 258-268.

62. Heyde GC. MODAPTS plus. Heyde Dynamics Pty. by arrangement with the Australian Association for Predetermined Time Standards \& Research; 1983.

63. Tiffin J, Asher EJ. The Purdue Pegboard: norms and studies of reliability and validity. Journal of Applied Psychology, 1948; 32(3): 234

64. Schult M, Söderback I, Jacobs K. Swedish use and validation of Valpar work samples for patients with musculoskeletal neck and shoulder pain. Work: A Journal of Prevention, Assessment and Rehabilitation, 1995; 5(3): 223-233.

65. Law M, Baptiste S, McColl M, Opzoomer A, Polatajko H, Pollock $\mathrm{N}$. The Canadian occupational performance measure: an outcome measure for occupational therapy. Canadian Journal of Occupational Therapy, 1990; 57(2): 82-87.

66. Collin C, Wade D, Davies S, Horne V. The Barthel ADL Index: a reliability study. Disability \& Rehabilitation, 1988; 10(2): 61-63. 
67. Chung KC, Pillsbury MS, Walters MR, Hayward RA. Reliability and validity testing of the Michigan Hand Outcomes Questionnaire. Journal of Hand Surgery, 1998; 23(4): 575-587.

68. Stanley BG, Tribuzi SM. Concepts in hand rehabilitation. $1^{\text {st }}$ ed. Philadelphia: F. A.Davis Company; 1992.

69. Brandsma JW, Schreuders TA, Birke JA, Piefer A, Oostendorp R. Manual muscle strength testing: intraobserver and interobserver reliabilities for the intrinsic muscles of the hand. Journal of Hand therapy, 1995; 8(3): 185-190.

70. Marx RG, Bombardier C, Wright JG. What do we know about the reliability and validity of physical examination tests used to examine the upper extremity? Journal of Hand Surgery, 1999; 24(I): I85-193.

\section{Corresponding Author}

\section{Susan de Klerk}

Division of Occupational Therapy,

Department of Interdisciplinary Health Sciences,

Stellenbosch University

sdk@sun.ac.za 